\title{
DEVELOPMENT OF TECHNOLOGIES OF REPAIR BY ARC WELDING OF OPERATING MAIN PIPELINES IN UKRAINE
}

\author{
V.S. BUT and O.I. OLEJNIK \\ E.O. Paton Electric Welding Institute, NASU \\ 11 Bozhenko Str., 03680, Kiev, Ukraine. E-mail: office@paton.kiev.ua
}

\begin{abstract}
In order to lower material-financial and ecological losses inherent to classical method of main pipeline repair, associated with their stopping, methods allowing main lines to be repaired without taking them out of service, are applied worldwide. The paper deals with the directions of development at PWI of technologies of restoring the load-carrying capacity of defective sections of the main pipelines under pressure with arc welding application. Analysis of the features of arc welding application on pipelines under pressure has been performed and ways to eliminate the unfavourable factors have been determined. Influence of welding heat on strength characteristics of pipe metal is shown, and safe conditions of welding-up corrosion defects are established, depending on thermophysical properties of the transported product and internal pressure magnitude. The paper presents an original design-technological approach to performance of repair operations with arc welding application, which is implemented on operating mail pipelines of Ukraine. Experimental-theoretical assessment of the advantages of application of overlap-butt welded joints over traditional joints with fillet welds is given. Results of investigations by polarization-optical method of stress concentration factors in the points of deposited metal transition to base metal are presented for various kinds of loading of simulation samples. Application of overlap-butt joints allows expansion of heat input range in arc welding; controlling the dimensions, structure and properties of HAZ metal; lowering concentration in the points of circumferential weld transition to the pipeline and thus improving the fatigue limit of welded joints of reinforcing structures at repeated static load. Normative-technical documents have been developed and introduced, which specify repair of the main pipelines under pressure with application of arc welding, and cases of practical application of the most effective design solutions are shown. 23 Ref., 10 Figures, 1 Table.
\end{abstract}

Keywords: main pipelines, arc welding, overlapbutt joints, pressure, safe welding conditions, heat input, strength characteristics, stress concentration factor, reinforcing structural elements, fatigue limit

Modern main pipelines are expensive facilities from low-alloyed higher-strength steels, designed for long-term operation of not less than 30 years. Therefore, high requirements are made to their reliable operation all over the world.

Safe operation of main pipelines (MP) is ensured by respective measures and means both at the stage of design and in operation. Among inservice measures, highly important is appropriate organization of periodical technical diagnostics of the state of MP elements and repair of detected inadmissible defects.

Classical repair of a pipeline, including its stopping, cleaning and replacement of defective sections, requires large material and financial expenses, and is also accompanied by considerable ecological damage. In this connection, technologies of MP repair without taking them out of service and, primarily, focused on arc welding processes, began to be developed at the end of the 20th century.

Features of arc welding application on pipelines under pressure. It is known that an arcwelded joint is the most readily made and reliable in operation. However, during welding operation performance on an operating pipeline there is the risk of through-thickness penetration or excess overheating of pipe wall by the welding arc that may lead to its rupture under inner pressure.

Results of testing conducted in the laboratory of British Gas Company showed that favourable conditions for pipe wall rupture under internal pressure during welding with low-hydrogen electrodes, are created at sufficiently high heat input [1]. So, in deposition of circumferential welds on a pipe with $4.7 \mathrm{~mm}$ wall thickness and with circumferential stresses $\sigma_{\theta}$ on the level of $0.72 \sigma_{\mathrm{y}}$ acting in it, fracture occurred at welding heat input not higher than $2.62 \mathrm{~kJ} / \mathrm{mm}$. With reduction of pipe wall thickness to $3.2 \mathrm{~mm}$, the probability of its rupture rises even at a small heat input (less than $1.51 \mathrm{~kJ} / \mathrm{mm}$ ), and in the case of making the weld along the generatrix it is less than $0.52 \mathrm{~kJ} / \mathrm{mm}$. Here, a considerable scatter 


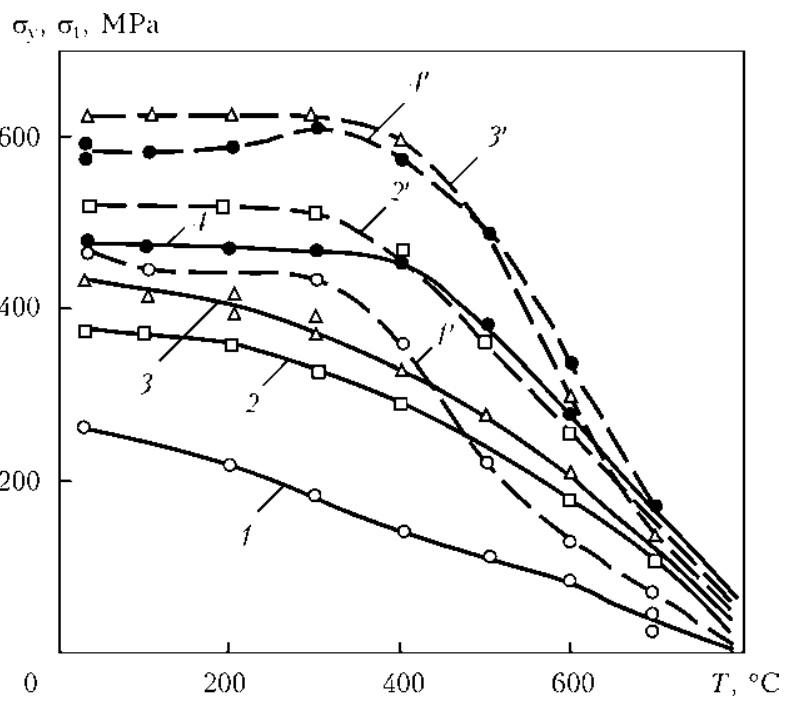

Figure 1. Influence of heating temperature on strength properties of studied steels: $1,1^{\prime}-$ steel $20 ; 2,2^{\prime}-14 \mathrm{KhGS}$; $3,3^{\prime}-17 \mathrm{G} 1 \mathrm{~S} ; 4,4^{\prime}-\mathrm{X} 60 ; 1-4-\sigma_{\mathrm{y}} ; 1^{\prime}-4^{\prime}-\sigma_{\mathrm{t}}$

of test results is recorded, particularly, when making longitudinal welds. All this is indicative of the high hazard of welding operation performance in pipelines under pressure.

Nature of variation of strength characteristics of some pipe steels, depending on heating temperature, as well as the possibility of arc welding performance on a pipeline at different parameters of internal pressure and heat input, have been quite well studied [2-4]. In the above-mentioned works it was found that heating of low-alloyed steels of $14 \mathrm{KhGS}, 17 \mathrm{G} 1 \mathrm{~S}, \mathrm{X} 60$ grades up to the temperature above $400{ }^{\circ} \mathrm{C}$ leads to an abrupt strength lowering, while at above $720{ }^{\circ} \mathrm{C}$, it becomes close to zero (Figure 1).

Obtained data are indicative of the fact that during welding on a pipe under pressure it is necessary to minimize its wall penetration and to reduce the zone of heating up to critical temperature. Admissible dimensions of the HAZ along the generatrix in arc welding on various diameter pipelines have been determined [5, 6]. It is found that with increase of pipeline diameter critical dimensions of the zone of heating up to limit temperature become larger. On the whole, however, these dimensions are small (Figure 2) that limits the capabilities of arc welding at metal deposition along the pipeline generatrix.

In [5] the procedure of calculation of pipes with surface corrosion damage was applied in determination of load-carrying capacity of a pipe under pressure during arc welding along the generatrix [7], as the nature of pipe rupture is identical in both the cases. The only question was what parameters of the zone of heating by the welding arc can be taken as the dimensions of the conditional surface defect, oriented along the

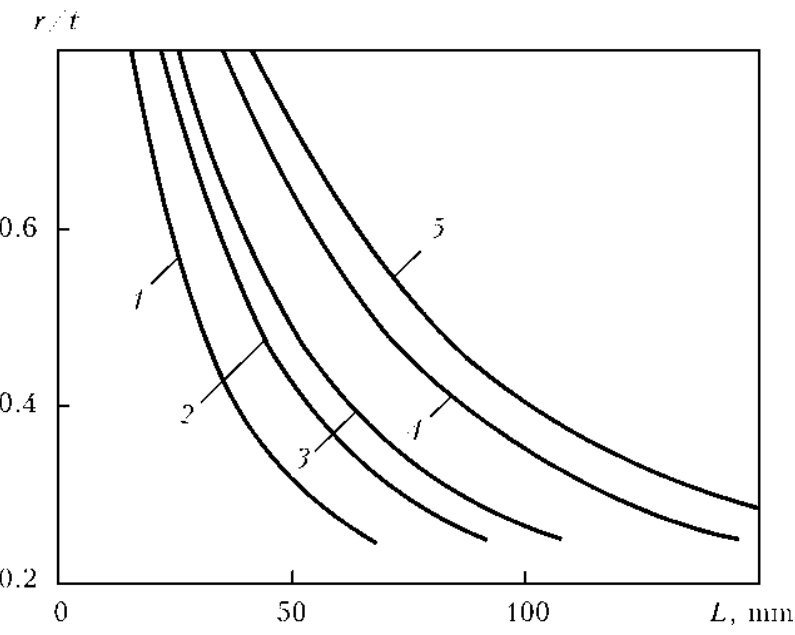

Figure 2. Admissible dimensions $L$ of zone of heating up to critical temperature in welding along generatrix for pipe with dimensions, $\mathrm{mm}: 1-325 \times 8 ; 2-530 \times 9 ; 3-$ $720 \times 9 ; 4-1020 \times 12 ; 5-1220 \times 12 ; r-$ maximum depth of the zone of pipe wall heating up to $720{ }^{\circ} \mathrm{C} ; t-$ pipe wall thickness

pipe generatrix. In one case it was possible to take the size of the zone of pipe wall heating up to melting temperature (weld pool size), and in another case - up to temperature above $720^{\circ} \mathrm{C}$, at which the metal strength characteristics are on a very low level. Moreover, what is important in practice is that this zone is readily determined visually on macrosections through the HAZ. Conducted testing showed that experimental data (Figure 3) are located much lower that the calculated values derived for a surface defect with weld pool parameters and somewhat higher than the values obtained for defects with dimensions of the zone of heating up to $720{ }^{\circ} \mathrm{C}$. And as was

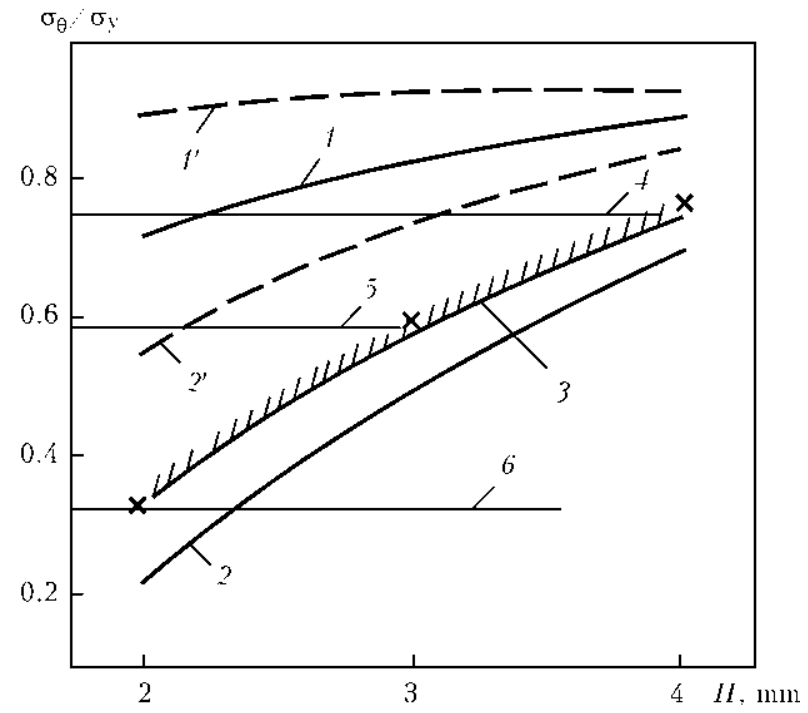

Figure 3. Relative level of breaking outer stresses $\sigma_{\theta} / \sigma_{\mathrm{y}}$ depending on thickness of unmelted bridge $H: 1,1^{\prime}-$ conditional defect of weld shape; $2,2^{\prime}-$ conditional defect with section of the zone of heating up to $700{ }^{\circ} \mathrm{C} ; 3-$ experimental data; $4-6-$ at $P=12,9.2$ and $5.3 \mathrm{MPa}$; $1-6-$ defect shape coefficient $C=1 ; 1^{\prime}, 2^{\prime}-C=2.3$ 
established, addition of the respective correction coefficient for deviation of heating zone longitudinal section from a rectangular shape allows obtaining a good agreement of experimental data with calculated values.

It should be also noted that the tendency to perform arc welding at low currents contradicts the requirements of producing HAZ metal of an acceptable hardness. As is known from [8] there is a high probability of cold cracking in welded joints with HAZ metal hardness above $H V 350$. In many countries a number of normative documents $[7,9,10]$ specify performance of multilayer fillet welds at mounting of sleeve fittings and branch pipes on operating pipelines. Here maximum HAZ metal hardness is achieved at external welds on the pipe as a result of cooling action of the transported product. And this hardness is the higher, the higher the speed of product pumping and the higher the pipe metal carbon equivalent $\mathrm{C}_{\mathrm{eq}}$. In [11] it is established that at gas pumping $\left(170,000 \mathrm{~m}^{3} / \mathrm{h}\right)$ through a pipeline from steel with $\mathrm{C}_{\mathrm{eq}}=0.4$, metal hardness in the HAZ reached $H V 415$, whereas at zero discharge it was $H V 285$.

In addition, the problem of making fillet circumferential welds is associated with inducing a rigid stressed state in the areas of branch pipe connection to the pipeline. In the presence of internal pressure these welded joints become vulnerable under the impact of mechanical deformations.

During circumferential welding, the evolving heat is quickly removed by the transported product, and this may lead to formation of quenching structures of martensite type in the HAZ metal. Therefore, it is necessary to apply additional heat to the welding zone for a long time. Manual propane torches are most often applied in practice, which preheat limited pipe sections up to $250{ }^{\circ} \mathrm{C}$. Welding is conducted until the temperature in the heating zone drops to $100{ }^{\circ} \mathrm{C}$. Then - heating again and subsequent welding.

Experimental investigations by Kiefner [12] confirm the probability of appearance of underbead cracks in fillet welded joints as a result of formation of quenching structures in the HAZ metal, presence of tensile stresses and diffusible hydrogen. To lower the risk of cold cracking, Kiefner proposes application of preheating and concurrent heating, as well as low-hydrogen electrodes.

Considering the very short period of heated pipeline sections staying in the range of acceptable temperatures (about $2-5 \mathrm{~min}$ ) at application of flame heating [12], other heat sources began to be actively introduced recently, such as electric heaters and inductors. Induction heating method and electric heaters have been tried out in nu- merous experiments and are successfully applied during repair operations on MP under pressure, allowing welding to be performed under the conditions of continuous heating [13].

In order to increase the safety of welding in operating pipelines and to be able to control the structure and properties of HAZ metal, as well as improve the reliability and performance of welded joints of reinforcing structural elements with pipelines, the authors of $[6,14]$ proposed a new design-technological approach with application of overlap-butt joints. Substantiation of such an approach will be given below.

Substantiation of the need for development of Ukrainian normative documents on repair of operating main pipelines. Already at the end of 1980s academician Boris E. Paton appreciated the urgency and attractiveness of development of repair technologies based on application of arc welding for restoring the load-carrying capacity of MP linear part and ensuring safe and undisturbed operation of transportation system. The first step in this direction were experimental investigations to determine the safe conditions of welding performance on a pipe with inner pressure [5].

In addition, in those years there was an urgent problem of gas supply to villages and urban-type villages located near the earlier constructed transit main gas pipelines, gas transportation through which could not be interrupted even for a minute. The problem posed for PWI staff was successfully solved owing to development and introduction first of the method of joining branchpipes to MP, based on application of explosion energy and bimetal transition piece [15], and then of a simpler and more reliable process of branchpipe connection by arc welding [5].

After USSR disintegration, Ukraine inherited a ramified network of pipelines for transportation of gas, oil and petroleum products. Total length of just the main pipelines, which are managed by company «Naftogaz Ukrainy», is more than $42,000 \mathrm{~km}$. Their main component is MP (more than $36,000 \mathrm{~km}$ ).

Considering the prolonged terms of pipeline operation, the problem of ensuring an effective and undisturbed operation of pipeline transportation is becoming ever more urgent. Its realization requires, primarily, improvement of currently available and development of new and reliable processes of work performance at MP repair and maintenance. To avoid financial-material losses and ecological damage, inherent to classical method of MP repair, techniques of repair without taking them out of operation are being developed all over the world. Such methods are 

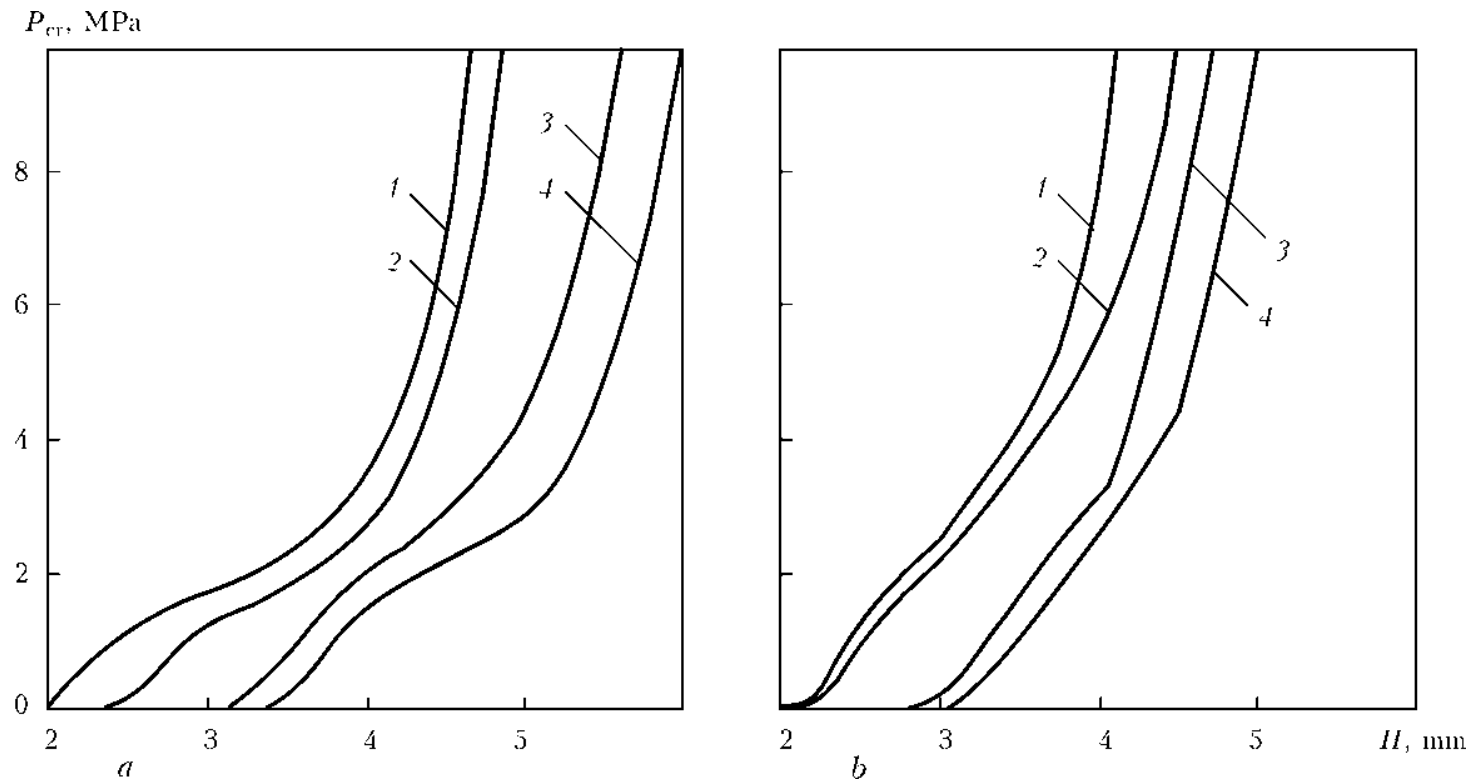

Figure 4. Dependence of critical pressure $P_{\text {cr }}$ on bridge thickness $H$ in welding-up cavities of $d=20(a)$ and $12(b) \mathrm{mm}$ in oil pipeline pipe of $1020 \times 11 \mathrm{~mm}: 1,2-I_{\mathrm{w}}=90 ; 3,4-140 \mathrm{~A} ; 1,3-$ oil transportation speed $W=6 ; 2,4-2 \mathrm{~m} / \mathrm{s}$

particularly important for Ukraine, considering the high concentration of population in the zone of main gas pipeline location, high gas price, and need for unconditional fulfillment of contractual obligations of gas supply to users both inside the country and abroad.

Moreover, now there is the need to develop a national normative document, which allows systematizing the approach to performance of repairreconditioning operations on MP under pressure with fulfillment of safety conditions and protection of environment, as well as ensuring the high quality, promptness and high standards of production cycle in keeping with the modern technology level.

Diagnostics of technical condition of main pipelines of Company «Ukrtransgaz», conducted using the intelligent pig of Rozen Company, showed that the largest number of detected de-

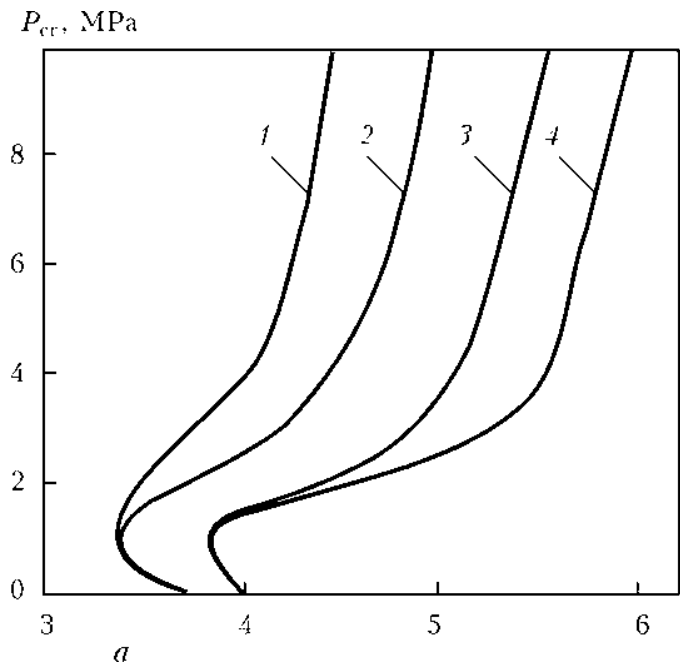

fects belong to surface corrosion damage of pipeline wall of «metal loss» type. So, metal losses of more than $60 \%$ of pipe wall thickness are equal to $0.9 \%$; 41-60\% - $5 \%$; 20-40\%$45.5 \%$. Defects of circumferential welds are equal to $10.8 \%$, surface defects - $11 \%$, longitudinal $-7 \%$, spiral $-0.9 \%$; base metal defects are $11.1 \%$, unclassified $-7 \%$, and anomalous kinds of defects are $0.8 \%$ [16]. In circumferential butt welded joints defects inadmissible, according to VSN 006-89 and VSN 012-88 requirements, were found, which were not detected during MP construction. Their number is more than $11 \%$ of all the detected defects. A multitude of surface defects in welds $(12 \%)$ and inner defects of delamination type $(11 \%)$ in base metal were found.

Proceeding from analysis of the nature and geometrical parameters of detected defects a comprehensive approach was proposed to develop-

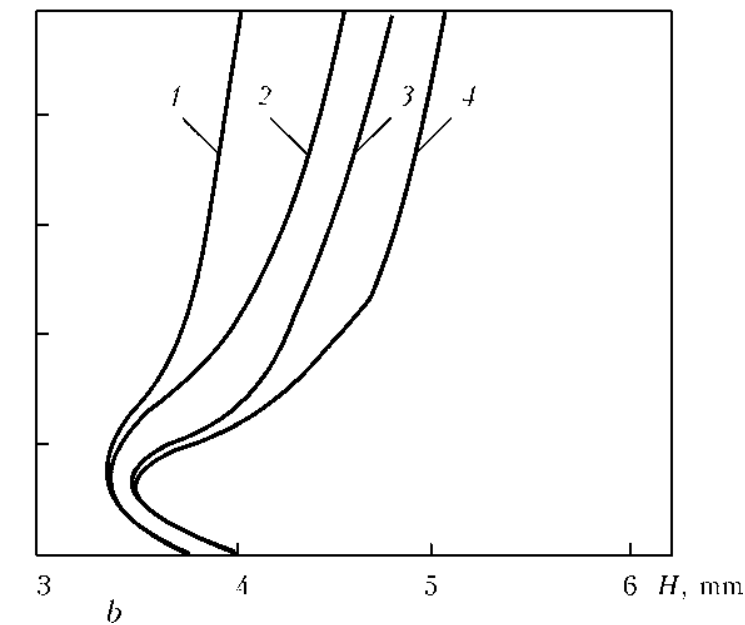

Figure 5. Dependence of $P_{\mathrm{cr}}$ on $H$ in welding-up cavities of $d=20(a)$ and $12(b) \mathrm{mm}$ in gas pipeline pipe of $1420 \times$ $\times 18 \mathrm{~mm}$ (designations are the same as in Figure 4) 
ment of technologies of restoration of the loadcarrying capacity of linear part of main gas pipelines (LPMGP) under pressure with arc welding application [14, 17]. Repair techniques were grouped by defect kinds and their purpose. For each group safe conditions of arc welding performance on MP under pressure are determined, allowing for working parameters and thermophysical properties of the transported product. Then conditions of ensuring the technological and structural strength of welded joints of the proposed reinforcing structures are the established.

Experimental-analytical evidence base of the advantages of proposed design-technological
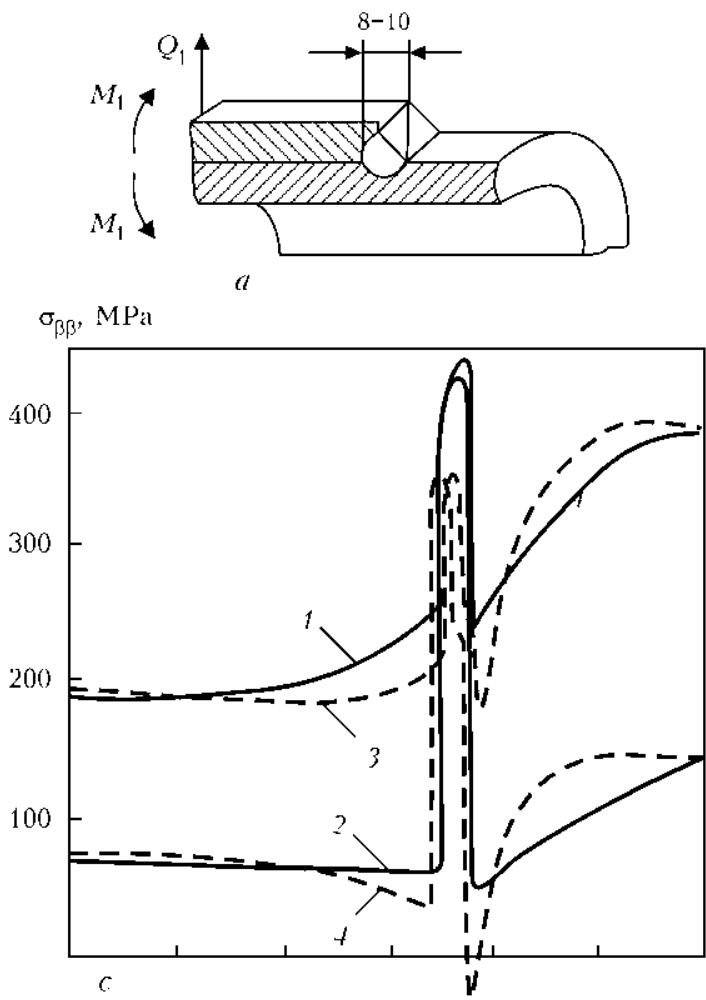

$\sigma, \mathrm{MPa}$

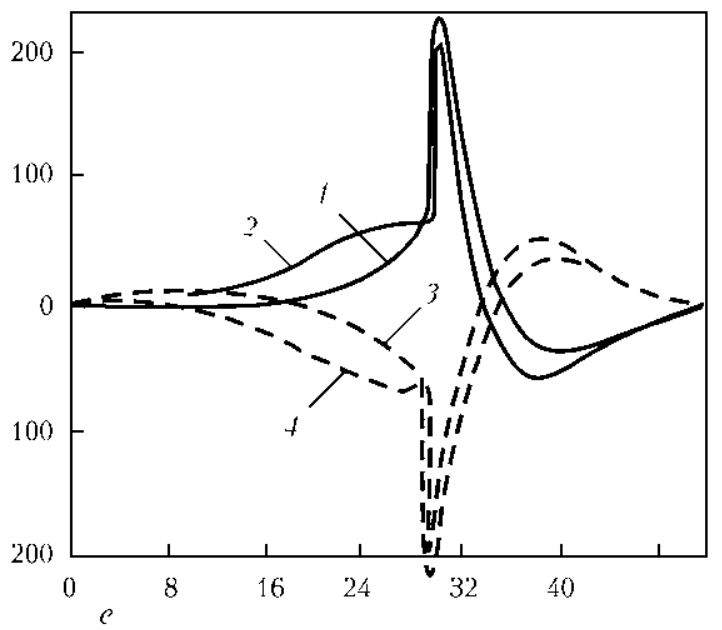

solutions. As was mentioned earlier, almost half of the detected defects on LPMGP are surface corrosion damage of a local nature. And, naturally, building-up by arc process is the simplest and most effective method to eliminate such individual defects. To provide mathematical substantiation of safe conditions of performance of building-up by arc process on pipelines under pressure, a nonstationary problem of heat conductivity [18] allowing for convective heat exchange on pipe wall inner surface depending on transported medium (gas, oil), was solved. Results of calculation of critical values of failure pressures for pipes from $17 \mathrm{G} 1 \mathrm{~S}$ steel of different
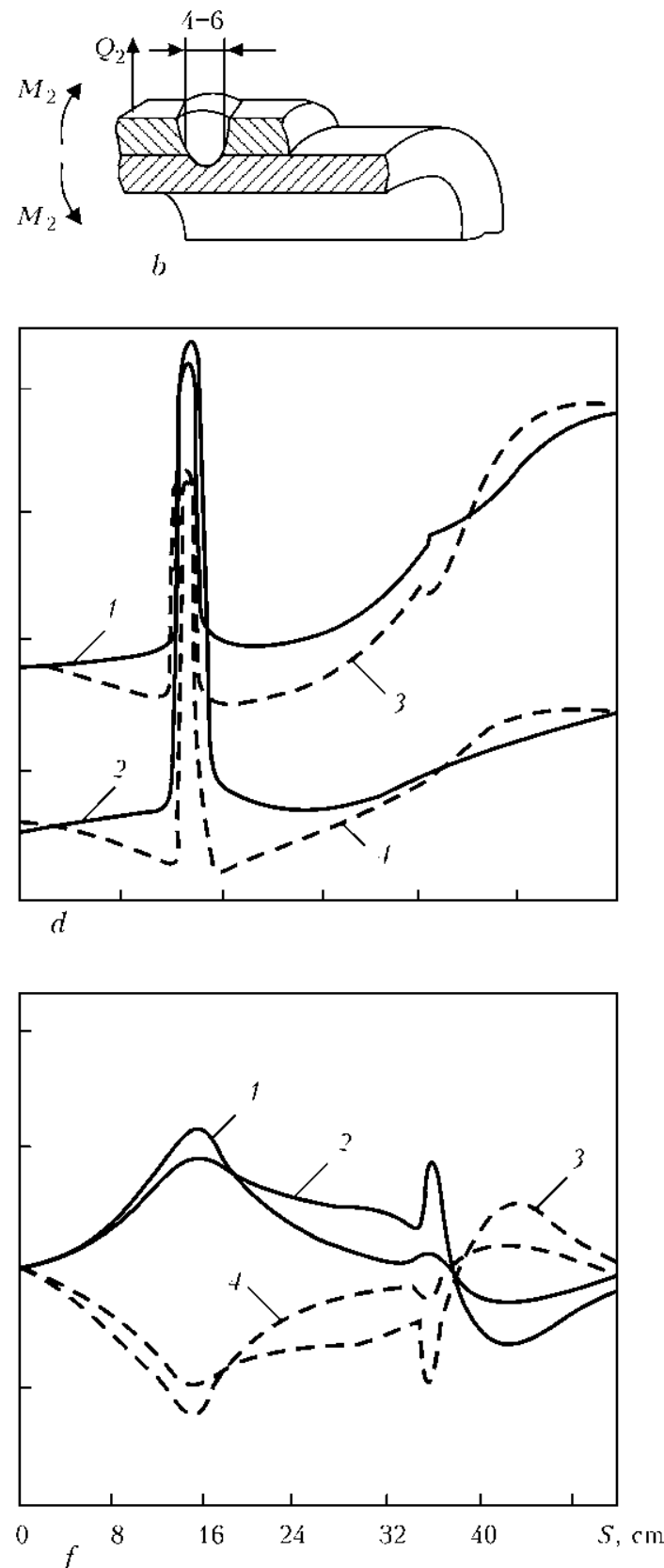

Figure 6. Influence of geometry on stress-strain state of welded joint: $a-$ with fillet weld; $b-$ overlap-butt; $c, d-$ distribution of longitudinal residual welding stresses $\sigma_{\beta}$ at internal pressure of $2.0(2,4)$ and $5.5(1,3) \mathrm{MPa} ; e, f-$ distribution of similar transverse stresses $\sigma_{s s} ; 1,2$ - outer surface of pipe wall; 3,4 - inner surface; $S$ - length of studied section 
diameter are presented in the form of graphical dependencies (Figures 4 and 5). These data show that for oil pipeline (Figure 4) the value of failure pressure rises monotonically with increase of metal thickness in the welding area up to certain limits, above which the considered failure mechanism (plastic instability) is not realized, as mean temperature across the thickness of the above-mentioned bridge is reduced abruptly. Reduction of welded up cavity diameter leads to reduction of bridge admissible thickness at the same pressure.

A similar situation is observed for gas pipelines (Figure 5). Here, however, the process is made more complicated by the high intensity of heat exchange between the wall and transported medium at low pressures, leading to nonmonotonic change of critical failure pressure, depending on bridge thickness.

Thus, it follows from the above-said that at welding up individual corrosion defects on MP under pressure the probability of bridge breaking up depends, primarily, on metal thickness in the welding area, as well as on transported product speed and its thermophysical properties, and internal pressure magnitude.

In order to restore the load-carrying capacity of LPMGP with extensive corrosion damage, crack-like defects, inadmissible defects in welds, design solutions were proposed, which are based on application of a new type of welded joint overlap-butt one [6]. As shown by investigations, a new original design approach to performance of repair operations in MP under pressure allows a considerable increase of welding heat input, with preservation of safe conditions of it performance. Only through-thickness burn of the wall can lead to depressurizing of the pipeline that is improbable in practice, as circumferential welds of reinforcing sleeves are made in pipeline sections with not less than $5 \mathrm{~mm}$ wall thickness [1].

Application of additional technological rings in overlap joints of sleeve with pipeline owing to reinforcing effect allows optimization of stressstrain state of welded joints, both under the impact of inherent welding stresses and of internal pressure (Figure 6). Load-carrying capacity and overall performance of welded joints under repeated-static loading depend on the level and nature of distribution of stresses in them.

Investigations of stress-strain state of samples of fillet and overlap-butt joints using polarization optical method at different kinds of loading [19] showed that in all the cases a higher stress concentration is observed in the areas of deposited metal transition to base metal in fillet welds ( $\mathrm{Ta}-$ ble). Obtained data correlate well with the results of testing simulation samples with different
Results of calculation of stress concentration $\alpha_{\sigma}$

\begin{tabular}{||l|c|c|}
\hline \hline \multicolumn{1}{|c|}{ Kind of sample loading } & Fillet joint & Overlap-butt joint \\
\hline Tension & $2.0-2.3$ & $1.8-2.0$ \\
\hline Three-point bending & $1.6-1.8$ & $1.2-1.3$ \\
\hline Cantilevered bending & $2.5-3.0$ & $1.2-1.5$ \\
\hline
\end{tabular}

weld geometries for fatigue resistance at repeated-static off-center tension [5]. Application of overlap-butt joints allows improvement of fatigue limit of welded samples 1.5 times compared to fillet weld joints (Figure 7).

In addition to the above-said, welding operation performance on pipelines under pressure using overlap-butt joints allows controlling HAZ dimensions, structure and properties. This reduces the probability of cold cracking and HAZ metal proneness to brittle fracture. In this case, complete automation of arc welding at joining of reinforcing elements to operating pipelines is possible [17].

In connection with the above-said, a number of design-technological solutions are proposed for restoration of load-carrying capacity of LPMGP with extensive corrosion damage without interrupting product transportation [20, 21].

The most characteristic examples of application of overlap-butt joints in reinforcing structures are sealed and two-layer sleeves (Figure 8). The latter are applied for reinforcement of pipeline defective circumferential butt joints, the majority of which are closing butt-«overlap» joints in construction.

Special consideration should be given to a structure with application of self-hardening compound based on polyurethane adhesive ( $\mathrm{Fi}^{-}$

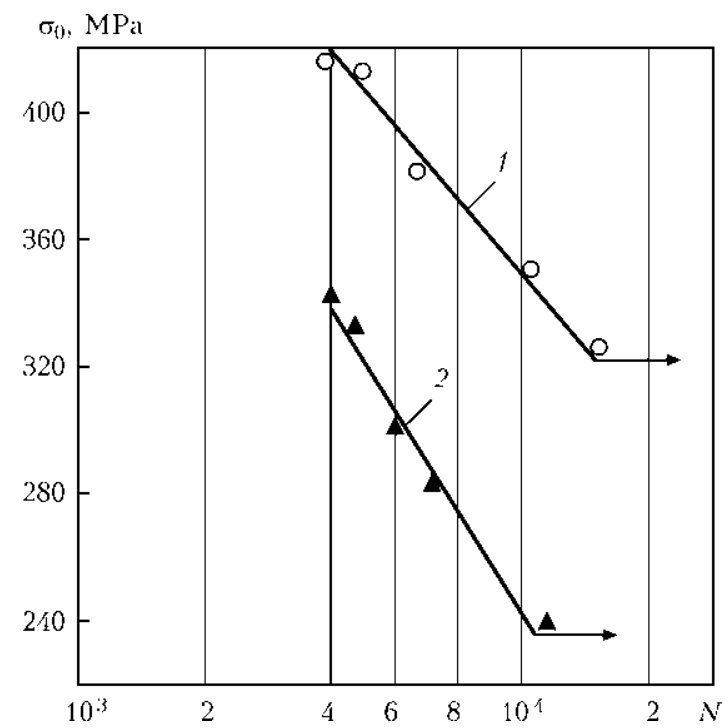

Figure 7. Results of testing welded samples at off-center repeated static loading: 1 - fillet; 2 - overlap-butt joints; $\sigma_{0}-$ sample fatigue limit; $N-$ cyclic fatigue life 

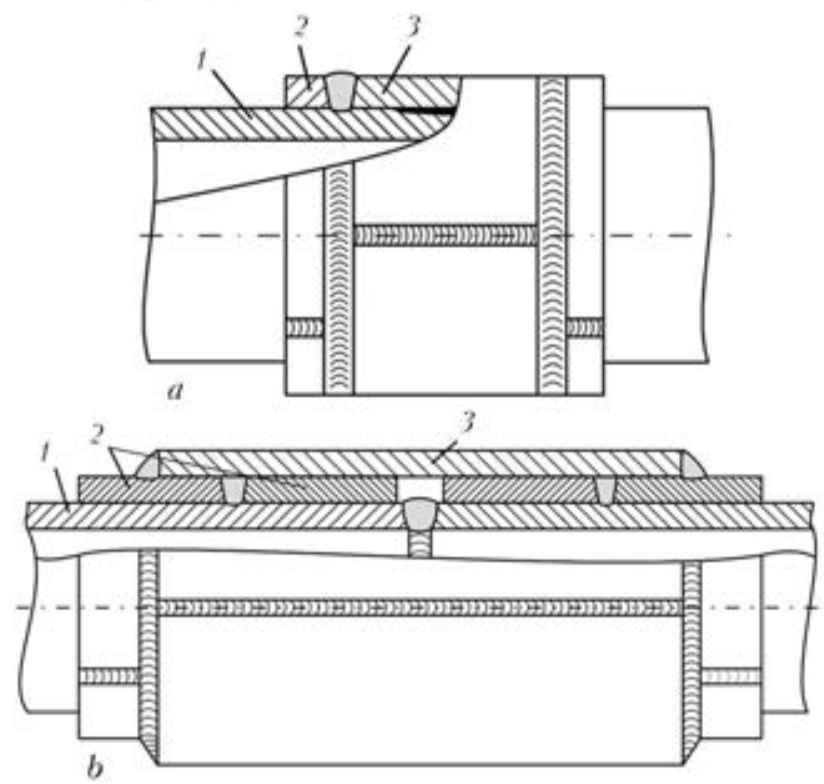

Figure 8. Design-technological schematics of MP repair under pressure using overlap-butt welded joints: $a$ - sealed $b$ - two-layer sleeve; 1 - pipeline; 2 - technological rings; 3 - sleeve

gure 9). In the authors' opinion, such an engineering solution is versatile and has considerable advantages over sealed sleeves, mounted directly on the pipeline and forming a sharp-angled stress raiser in the form of an interlayer gap between the sleeve and pipe in the circumferential weld area.

Application of additional thin-walled rings from flux-cored strip allows blunting the above stress raiser and thus lowering the stress level in

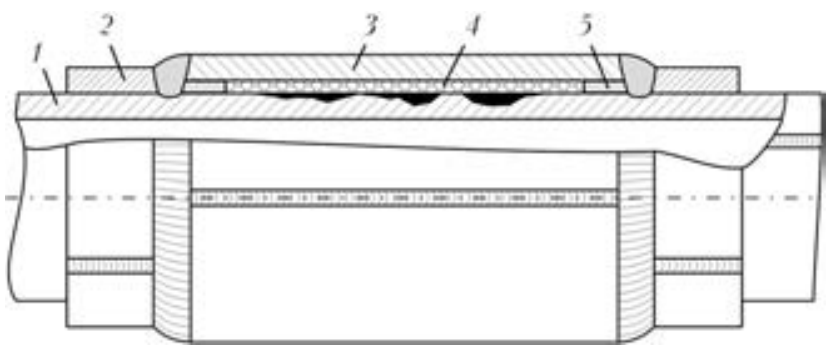

Figure 9. All-purpose bond-welded sleeve on thin backing: 1-3 - designations are the same as in Figure 8; 4 - adhesive composition; 5 - metal strip

the critical zone during formation of a circumferential weld. This results in lower probability of cold cracking in welds at the raiser. Moreover, application of thin-walled rings allows eliminating the need for making grooves on sleeve inner surface for pipeline longitudinal welds that simplifies the repair process and improves its quality, as well as lowers the probability of repaired structure failure. An essential advantage of the considered structure is the possibility of filling the undersleeve space by an adhesive self-hardening mixture under pressure, commensurate with working pressure in the pipeline. This allows lowering stress level in pipeline defective part, transferring the load to sleeve. Moreover, such an approach allows repairing extended MP sections due to mounting multisection weld-bonded sleeve [21] and can be advantageous, if it is required to increase the category of individual sections of operating gas pipeline.
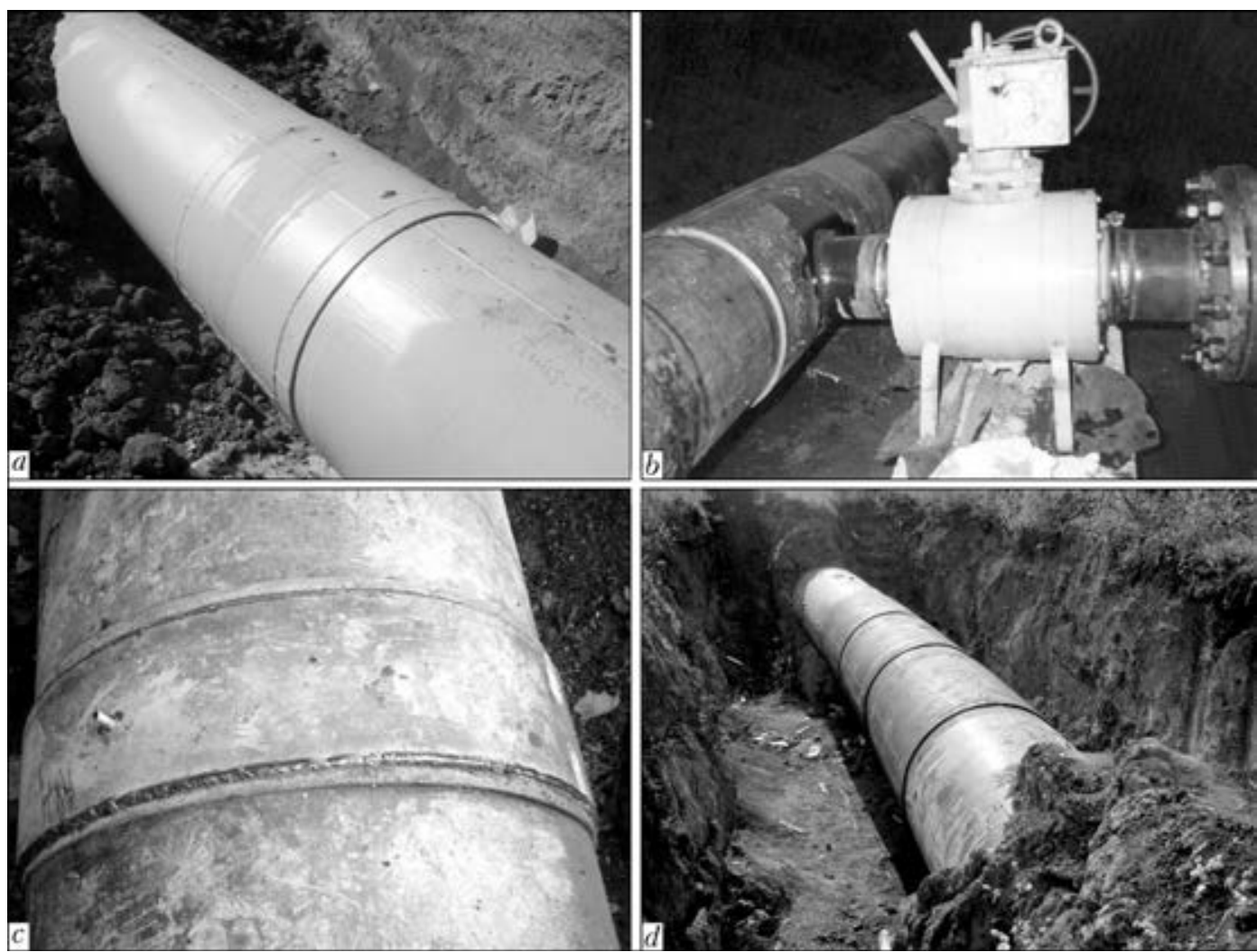

Figure 10. Mounting of sealed sleeve $(a)$, branchpipe $(b)$, two-layer sleeve $(c)$ and bond-welded sleeves $(d)$ on MP 
Practical experience of developed technology application. Groundwork on experimentaltheoretical substantiation of design-technological solutions application for repair of operating $\mathrm{MP}$, first in a smaller volume, was the basis for normative document VBN V3.1-0001374107:2007 for oil pipelines [20]. And later on, it was more completely incorporated into GBN B.3.1-00013741-12:2011 for gas pipelines [21]. In order to unify the approach to manufacturing reinforcing structural elements, TU U 27.219305558-001:2007 were developed [22].

For training and certification of personnel performing repair operations, respective programs were developed, both for welders and for welding operation supervisors, as well as training manual on repair techniques with application of arc welding on pipelines under pressure [23].

During the period of wide application (20012012) of the developed technologies in the facilities of «Ukrtransgaz» the following operations were performed: 326 two-layer sleeve fittings were mounted on defective butts of the main pipelines, 52 branchpipes were joined to the main line for connection of new consumers, more than $800 \mathrm{sec}-$ tions with considerable corrosion damage were repaired, using weld-bonded sleeves. Figure 10 gives examples of practical realization of the developed technologies. Overall economic effect from their introduction was greater than UAH $188 \mathrm{mln}$.

Successful cooperation of «Ukrtransgaz» and PWI teams allowed receiving more than 50 patents of Russia and Ukraine for a number of engineering solutions. Achievements in the field of systemic approach in development of technologies of repair of operating main pipelines have been rewarded by State Prize of Ukraine in the field of science and technology for 2008.

\section{Conclusions}

1. Analysis of the features of arc welding application in MP under pressure was performed and ways to eliminate the impact of adverse factors have been determined.

2. In order to extend MP safe operation, as well as considering the high population density in the zone of main line running and the need to ensure an undisturbed supply of energy carriers to users, industrial normative-technical documents have been developed on MP repair by arc welding in operation.

3. Advantages of the new design-technological approach at restoration of load-carrying capacity of defective areas of LPMGP in operation have been demonstrated. Application of overlap-butt joints allows widening heat input range in arc welding; controlling the dimensions, structure and properties of HAZ metal; lowering stress concentration in the area of circumferential weld transition to the pipeline and, thus, increasing the fatigue limit of welded joints of reinforcing structures at repeated static loading.

1. Bruce, W.A., Mishier, H.D., Kiefner, J.F. (1993) Repair of pipelines by direct deposition of weld metal. AGA Pipeline Res. Com. Project PR-185-9110. Edisson Weld. Inst.

2. But, V.S., Gretsky, Yu.Ya. (1997) On problem of joining of branchpipes to main pipelines in service conditions. Avtomatich. Svarka, 6, 25-33.

3. But, V.S., Gretskii, Yu.A. (2001) Repair of the main pipelines under pressure using arc welding. In: Proc. of Int. Conf. on Pipeline Repairs (Australia, 5-6 March, 2001).

4. Makhnenko, V.I., But, V.S., Kozlitina, S.S. et al. (2010) Risk of fracture of pressurised main pipeline with defects of the type of wall thinning during repair. The Paton Welding J., 1, 7-10.

5. But, V.S. (1991) Joining of branchpipes to main oil pipelines under pressure using arc welding. In: Petrol. Industry. Series Transport and oil storing. Moscow: VNIIOENG.

6. But, V.S., Rozgonyuk, V.V., Gretsky, Yu.Ya. et al. (2001) Validation of new approach to performance of welding operations on pipelines under pressure. Naft. i Gaz. Promyslovist, 4, 33-39.

7. (2007) ASME B31.8: Gas transmission and distribution piping system. Amer. Soc. of Mech. Eng.

8. Hrivnak, I. (1984) Weldability of steels. Moscow: Mashinostroenie.

9. (2007) CSA Z662-07: Oil and gas pipeline system. Canadian Stand. Assoc

10. (2006) BS EN ISO 16708: Petroleum and natural gas industrials. Pipeline transportation systems. Reliability-based limit state methods.

11. Phelps, B., Cossie, B.A., Evans, N.H. (1986) Welding onto live natural gas pipelines. J. Metal Construction, 8, 350-354.

12. Kiefner, J.F., Maxey, W.A. (1989) Test validate pipeline sleeve repair technique. Oil and Gas J., 8, 47-52.

13. Korolkov, P.M. (1996) Heat treatment of pipeline welded joints in field conditions. Montazhn. i Spets. Raboty v Stroitelsve, 11/12, 21-24.

14. Bekker, M.V., But, V.S., Govdyak, R.M. et al. (2008) Repair of main pipelines under pressure. Kyiv: Kyj.

15. Dobrushin, L.D. (1981) Development and investigation of the technology of welding branchpipes of main gas pipelines under pressure using explosion energy: Syn. of Thesis for Cand. of Techn. Sci. Degree. Kiev.

16. But, V.S., Gretsky, Yu.Ya., Drogomiretsky, M.M. et al. (1998) Evaluation of corrosion damages and application of arc welding for repair of operating pipelines. Naft. $i$ Gaz. Promyslovist, 6, 44-47.

17. But, V.S., Olejnik, O.I. (2007) Main trends in technology for repair of active pressurized main pipelines. The Paton Welding J., 5, 30-35.

18. Makhnenko, V.I., But, V.S., Velikoivanenko, E.A. et al. (2001) Mathematical modelling of pitting defects in active oil and gas pipelines and development of a numerical method for estimation of permissible parameters of arc welding repair of defects. Ibid., 11, 2-9.

19. But, V.S., Velikoivanenko, E.A., Pochinok, V.E. et al. (1988) Investigations of stress-strain state and prediction of serviceability of welded joints of structural elements with pipeline. In: Improvement of control and service systems of main oil transportation: Transact. Ufa: VNIISPTneft, 189-196.

20. $V B N$ V.3.1-00013741-07:2007: Main oil pipelines. Methods of repair of defective zones. Valid 01.01.07. Kyiv: Ministry of Fuel and Energy of Ukraine.

21. GBN V.3.1-00013741-12:2011: Main gas pipelines. Repair using arc welding in service conditions. Valid 06.09.11. Kyiv: Ministry of Energy and Coal Industry of Ukraine.

22. TU U 27.2-19305558-001:2007: Reinforcing structural elements of pipelines. Valid 03.07.07.

23. But. V.S. (2003) Construction and repair of operat ing main gas pipelines. Manual for supervisors of welding operations on main pipelines under pressure. Kiev: PWI ITCC. 